\title{
A new tolerance analysis approach for deformable assemblies: an industrial case study
}

\author{
Hafsa Atik $^{* 1}$, Mouhssine Chahbouni ${ }^{* 2}$, Driss Amegouz ${ }^{* 3}$ and Said Boutahari ${ }^{* 4}$ \\ *High School of Technology of Fez, \\ University sidimohamed ben abdellah B.P 2626 -Route d'Imouzzar, 30000 Fez, Morocco. \\ ${ }^{1}$ hafsa.atik@usmba.ac.ma \\ ${ }^{2}$ mouhssine.chahbouni@usmba.ac.ma \\ ${ }^{3}$ driss.amegouz@usmba.ac.ma \\ ${ }^{4}$ said.boutahari@usmba.ac.ma
}

\begin{abstract}
A new approach which is based on the Method of Influence Coefficients is proposed to increase the quality of the compliant assembly. The purpose of this article is to conduct a theoretical and practical study that aims to illustrate the influence of spot welding, contact between surfaces as well as shape defects on the analysis of tolerances of flexibles parts and assemblies. The example treated is an industrial assembly of the automobile.
\end{abstract}

Keyword - Tolerance analysis, compliant assembly, Influence CoefficientsMethod, surface contact, shape defects

\section{INTRODUCTION}

Modern manufacturing processes are strongly influenced by the variation of flexible parts and their manufacturing processes. The effect of these variations is strictly related to deviations of parts, assembly sequence, assembly constraints, flexibility of parts, all these factors combine in a way that affects the quality of the final product. Including the final shape of the desired assembly, the task of design becomes a crucial task to realize to reduce costs and production times.

Several works proposed different solution to face this problem [1] [2] [3] [4] [5] [6] [7] [8] [9] [10] [11], and they validate they approach with industrial or aeronautic case studies. An industrial case study of a trellis supporting cables and pipes for an airplane has been dealt with Alain Stricher's thesis and article [12] [13]. These results make it possible to identify on the one hand the defects that are detrimental to the static conformity of the lattice in the assembled state, and for which they have been able to envisage limiting the tolerances, and on the other hand, those whose impact is negligible enough that we can afford to extend the tolerances. In [14] another case study was treated in order to validate his proposition of the concept of source of variation and the Method of Influence Coefficients. Kristina Wärmefjord [15] validated these studies concerning her method for including the welding sequence in the variation simulation, thus investigating the number of weld points required to lock the geometry, i.e. the number of geometry points required. The surveys are based on industrial case studies. The article by Ali Hashemian [16], [17] aims to develop a new methodology for the analysis of the variation of flexible metal parts and assemblies based on nonlinear contact analysis and including the effect of geometric covariance. The methodology proposed in this work incorporates nonlinear finite element analysis with improved risk-free probability analysis to predict variation in final assembly. The effectiveness of the approach developed is evaluated by an experimental case study as well as the Monte Carlo simulation. For the continuous improvement and increase of the accuracy of dimensional variation analysis for non-rigid assemblies by contact modeling, [18] to develop a systematic procedure of nonlinear dimensional variation analysis for assemblies of sheet metal using the method of finite elements by contact and the taking into account of the friction force between the assembly surfaces. The proposed approach is validated in a case study of two assemblies of sheet metal parts by physical experiments. In our work [19] and [20] we studied a model of simulation of the variation of deformable (flexible) mechanisms, using the Method of Influence Coefficients taking into account the effects of contact between the surfaces and including welding distortion in the first work, then in the second work we proposed a new strategy to take into account the shape defect. A case study of the both propositions is validated through an example with a view to an analysis of tolerances. 
The present work proposes the integration of the different variation affects the tolerance analysis of flexibles assemblies. A theoretical study is proposed to illustrate the influence of spot welding, contact between surfaces as well as shape defects on the analysis of tolerances of flexibles parts and assemblies using Method of Influence Coefficients. Then an experimental validation of the results of flexible assembly simulation was made within the automotive example, for the front part of the $\mathrm{X}$ vehicle. It is thus necessary to confront the result of the simulation of the assemblies, which would make possible to conclude the performances of the proposed method for the analysis of flexible assembly. And this would also validate the variation prediction methods that have been studied in this article.

\section{PROPOSED METHOD}

The proposed method is to combine between three parameters: the contact area, shape defect and the welding distortion using the Influence Coefficient Method.

This new approach is to have a more accurate tolerance analysis for a study more trustworthy. To do that we propose to calculate the variation of the plates $\mathrm{Vu}$, but this time by combining the first natural modes to introduce the shape defect, the variation of the plates will be expressed as a vector $\{\mathrm{Vu}\}$. Then we integrate the shape defects using the method proposed in the article [7], after that we check the conformity of the assembly or more precisely the contact area to prevent the penetration between the parts with our approach which consists in defining a temporary assembly plan. The calculation of this plan is based on the assumption that the first contact between the surfaces is in the plane constructed by three points whose characteristics are:

- The point that represents the greatest displacement,

- The point that represents the smallest displacement

- The point which is before the point whose displacement is the smallest according to the axis of study.

The equations that present this proposed are:

Unilateral contact condition: $\mathrm{gn} \geqslant 0$,

Compression condition: $\mathrm{pn} \leqslant 0$,

Supplementary condition: $\mathrm{pn} \cdot \mathrm{gn}=0$,

Here pn indicates the normal contact force

And gn is the normal contact distance

Then we simulate the assembly by adding welding effects using the Influence Coefficient Method, we solve the following equation.

$\left\{\mathrm{U}_{\mathrm{w}}\right\}=\left[\mathrm{S}_{\mathrm{u}}\right]\left\{\mathrm{V}_{\mathrm{u}}\right\}+\{D\}$

$\left\{\mathrm{V}_{\mathrm{u}}\right\}$ The part variation

$\left\{U_{w}\right\}$ The assembly deviation

$\left[\mathrm{S}_{\mathrm{u}}\right]$ The sensitivity matrix

$\{D\}$ welding distortion

The steps as explained before are summarized in the following figure 1: 


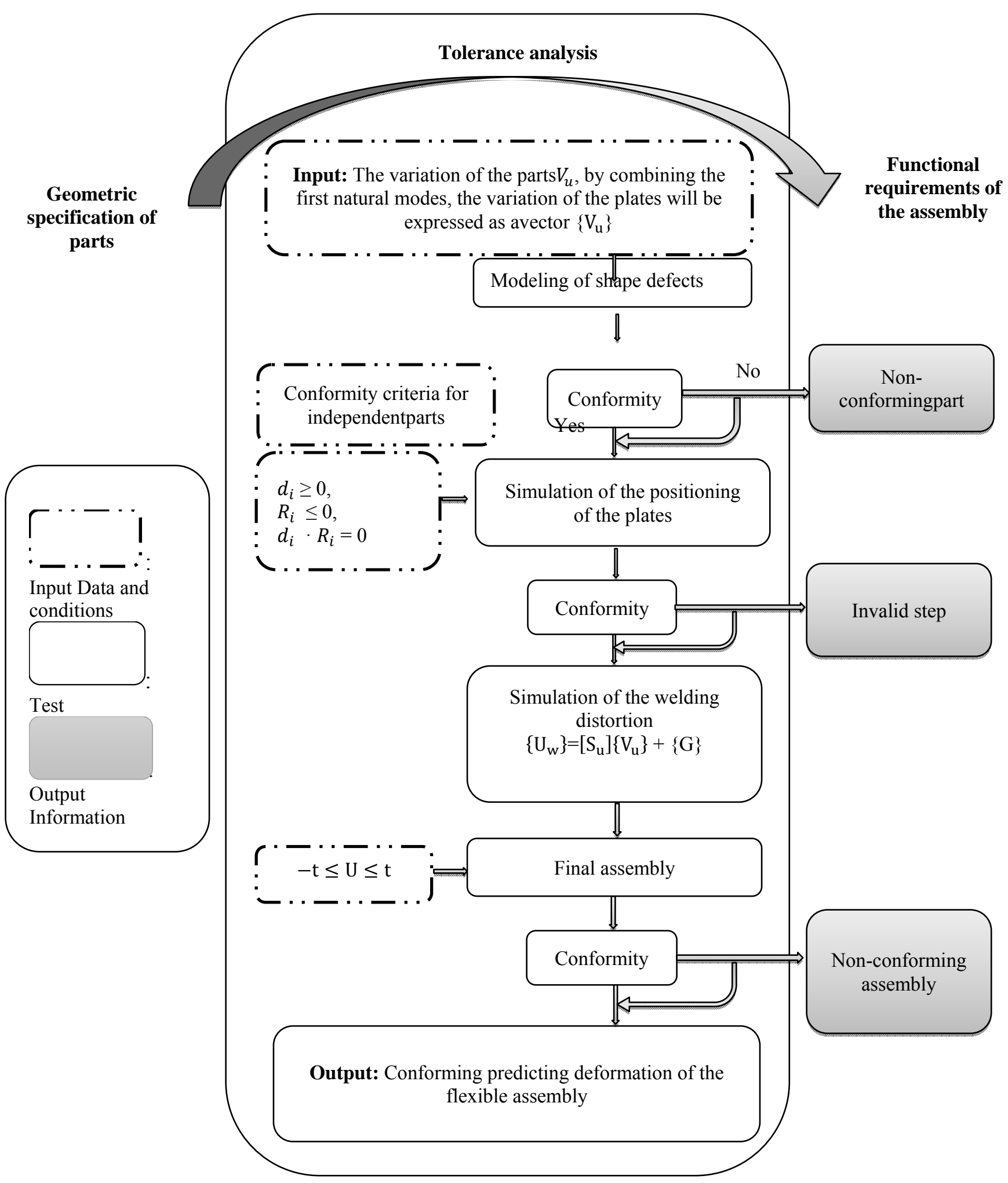

Fig. 1. algorithms of the analysis of a flexible assembly 


\section{Presentation of The CASE StUdy}

The industrial application intended for the validation of research work presented previously, it consists of a tolerance analysis of the front part of the vehicle body which consists of several parts that are considered nonrigid. The design of the crate is given not the engineering department. This box must be assembled in a way that allows the windshield to be assembled without problems with sealing or tightening which causes cracks during the assembly process. The figure 2 shows the geometric model of this part in front of the box.

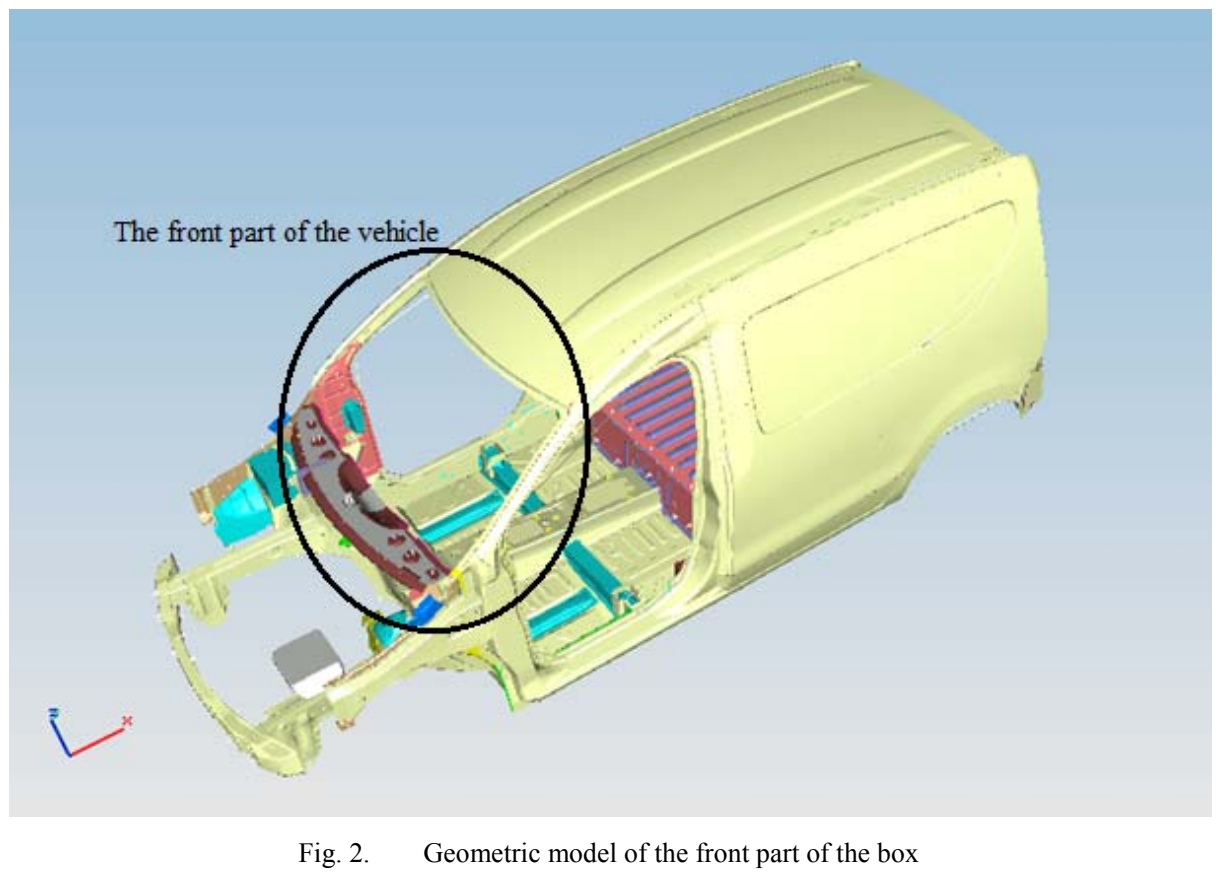

\section{A. Tolerance analysis}

The objective is to estimate the propagation of the variation of the parts to their assemblies using the method of the coefficients of influence taking into account the methods of assembly, in this case the spot welding. To compare the simulation results with the results of the actual strain measurements.

\section{1) Simulation}

Random variables are generalized for the variation sources $\{\mathrm{V}\}$ according to a normal distribution for each piece, 1000 random prints are made for which the sensitivity matrix is calculated using the proposed coefficient of influence method. We calculate the control parameters for each room, in our case we calculate the displacements of the extreme points of the surface concerned as well as the displacements of the extreme points of their assemblies using the following equation:

$$
\{U\}=[S]\{V\}+\{D\}
$$

For checking the conformity of the assemblies, the control parameters must remain within the tolerance range, this is represented with the following inequalities:

$$
-t \leq U \leq t
$$

In the analysis of the variation of the flexible parts, the sources of variation are generally the initial deviations of the components. To facilitate the calculation, it is common to select some points on the components and consider their corresponding deviations as input variables. In the present study, the initial deviation of the points $3,4,6,16,21,64,66,90,111,112$ on the right-hand side (figures 3 and 4). The points 3, 4, 6, 16, 21, 64, 66 90, 111,112 on the left-hand side (figures 5 and 6 ). The points $1,21,23,38,53,84,101,103,121,123,153$ for the flag (figure 7) and 1, 4, 11, 12, 22, 41, 101, 111, 121, 122, 141 for the item Tibe closure element (figure 8) are the input variables in our study. finally the variation of points $1,2,3,4,7,8,9,10,12,13,14,15,16,17,18,19,21$, $22,101,102,103,104,105,106,107,108,109,110,111,112,113,114,115,116,117,118,119,121,122,123$, 124 are the outputs of our study as it is presented in figure 10.

\section{2) Real case}

- Variation of parts

The 3D control is done after stamping the parts in the factory, to check the conformity of these parts to be assembled later. An example of control of the right-hand side is presented in the following figures, as well as its deviation measurement history of its points an example is presented in the fig $8,9,10,11,12$. In the following figure an example of control history of a point among the points of interest in this study. 


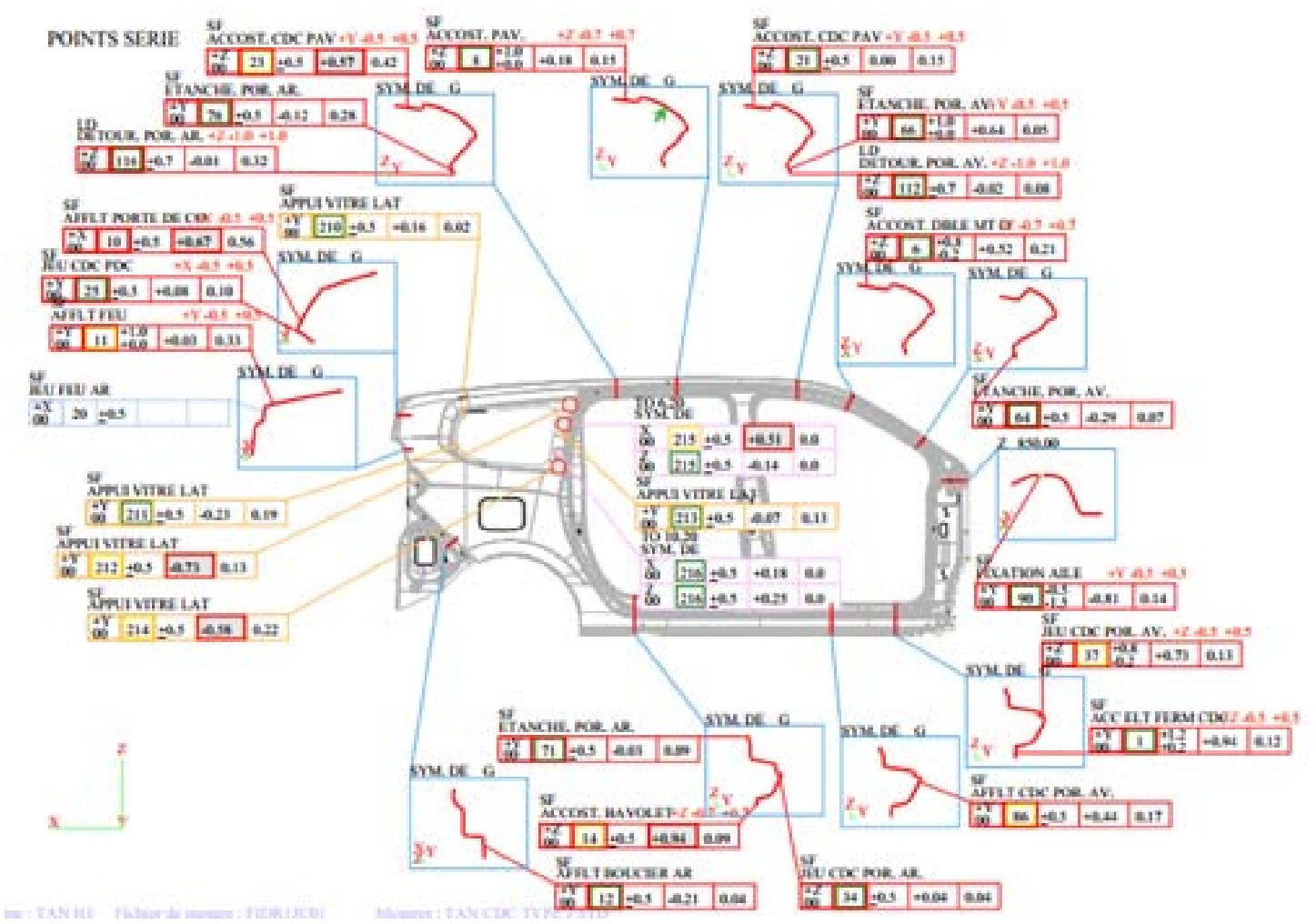

Fig. 3. Control points on the right side of the box and the mean and range of the deviation of each point (plate 2/6)

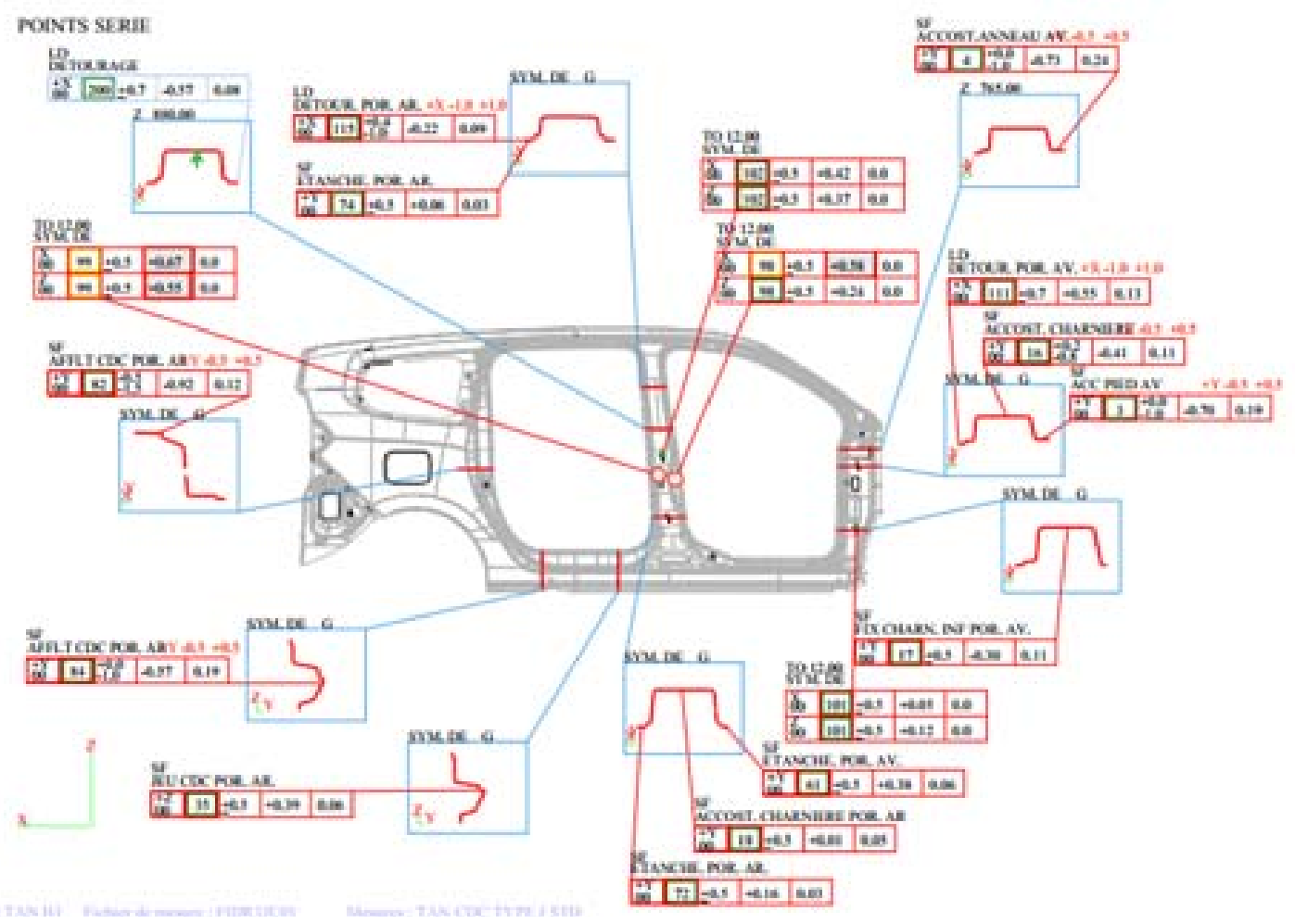

Fig. 4. The average and the extent of the control point deviation on the right box side (board 3/6). 


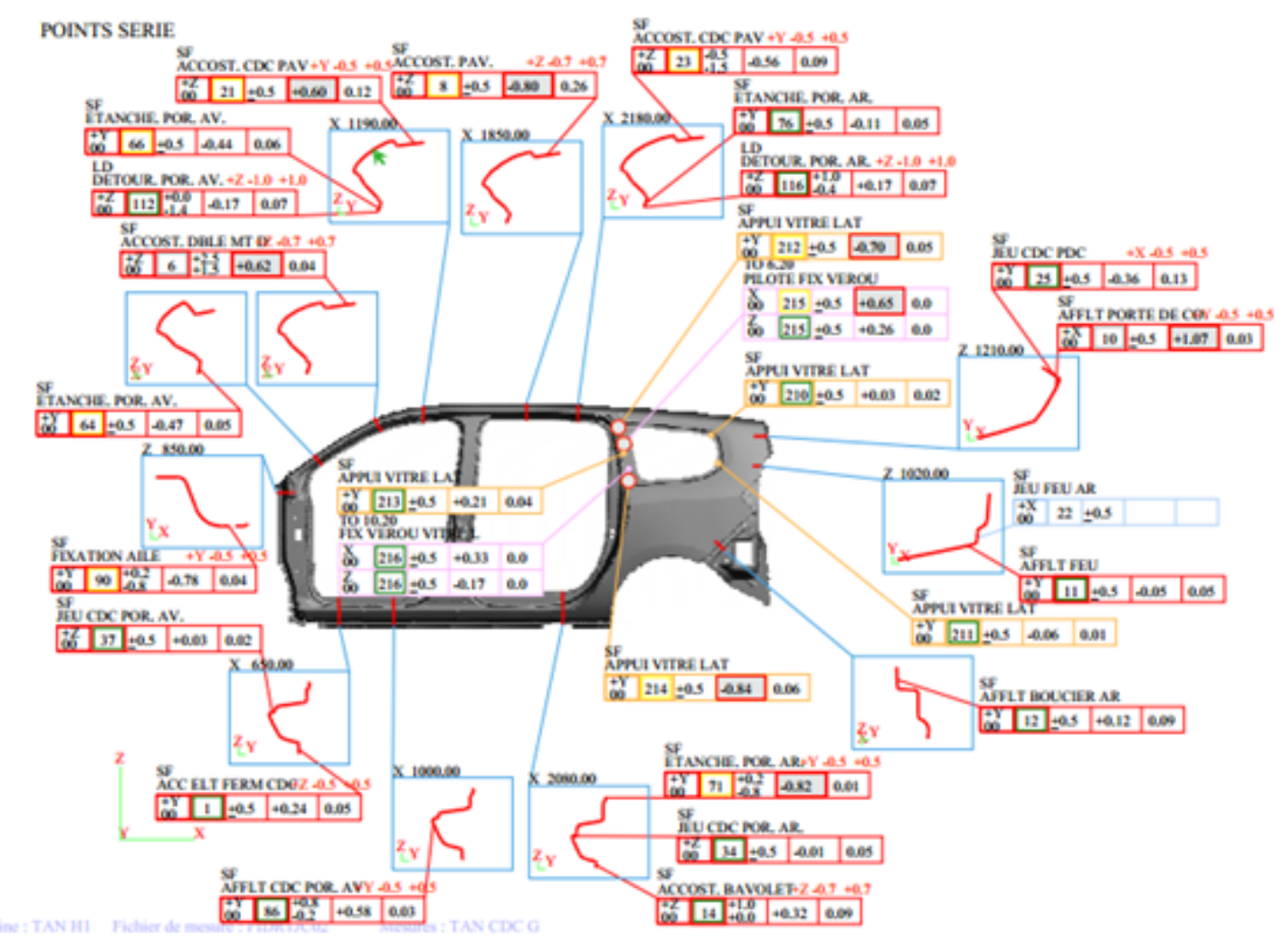

Fig. 5. The average and the extent of the control point gap on the left side (Plate 2/5)

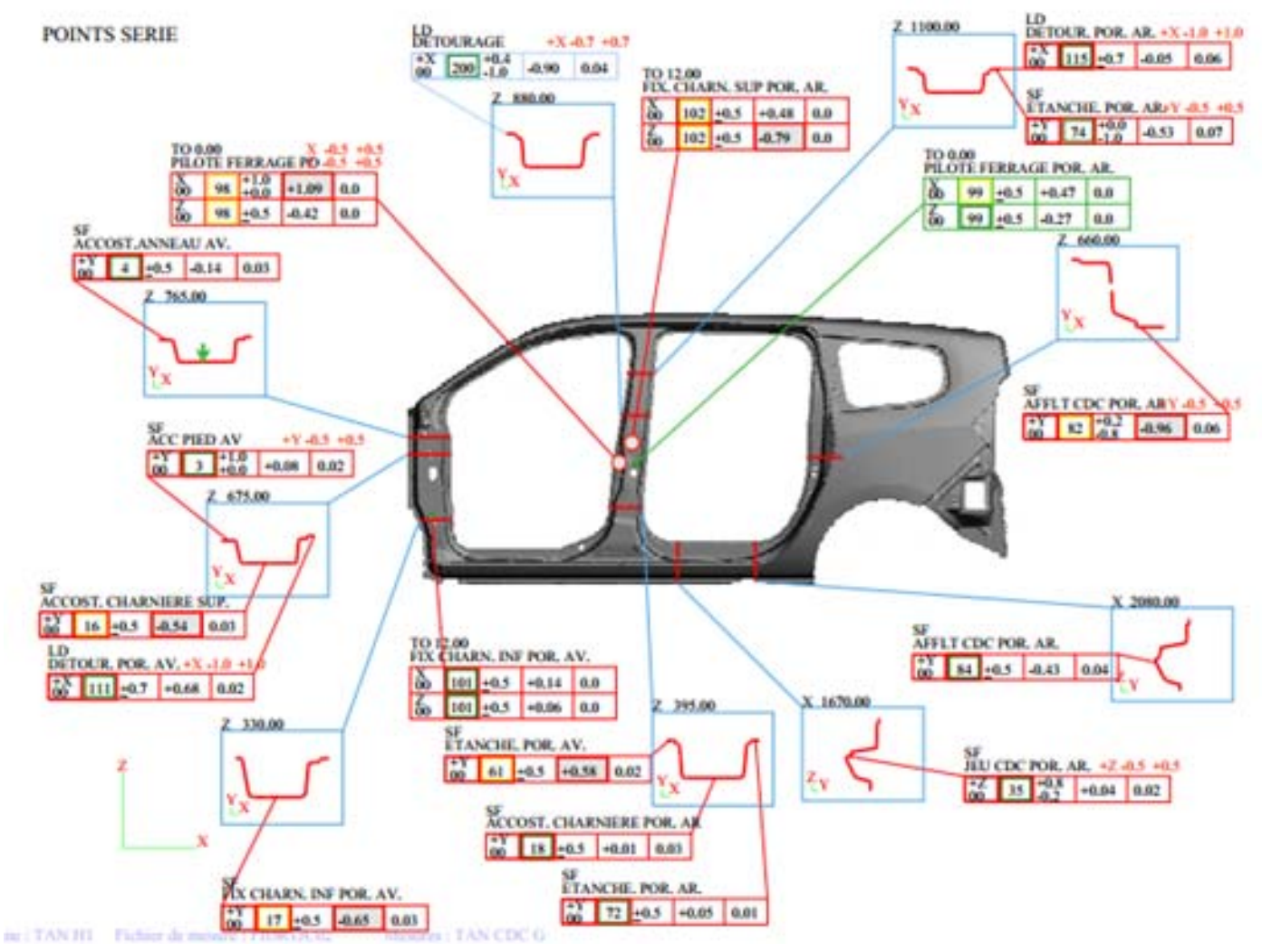

Fig. 6. The average and the extent of the control point gap on the left side (Plate 3/5) 


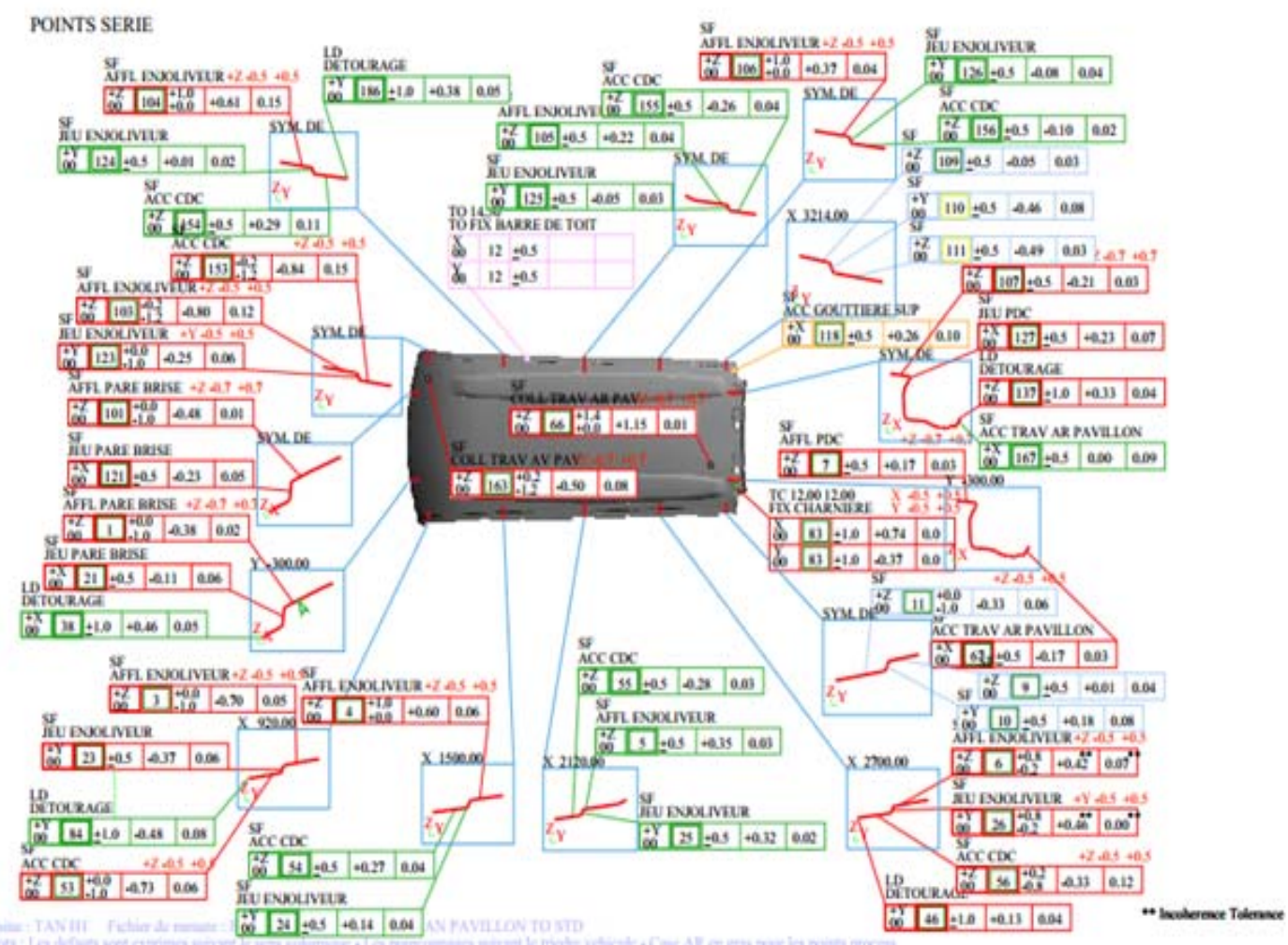

Fig. 7. The average and the extent of the control point gap (Plate 2/3)

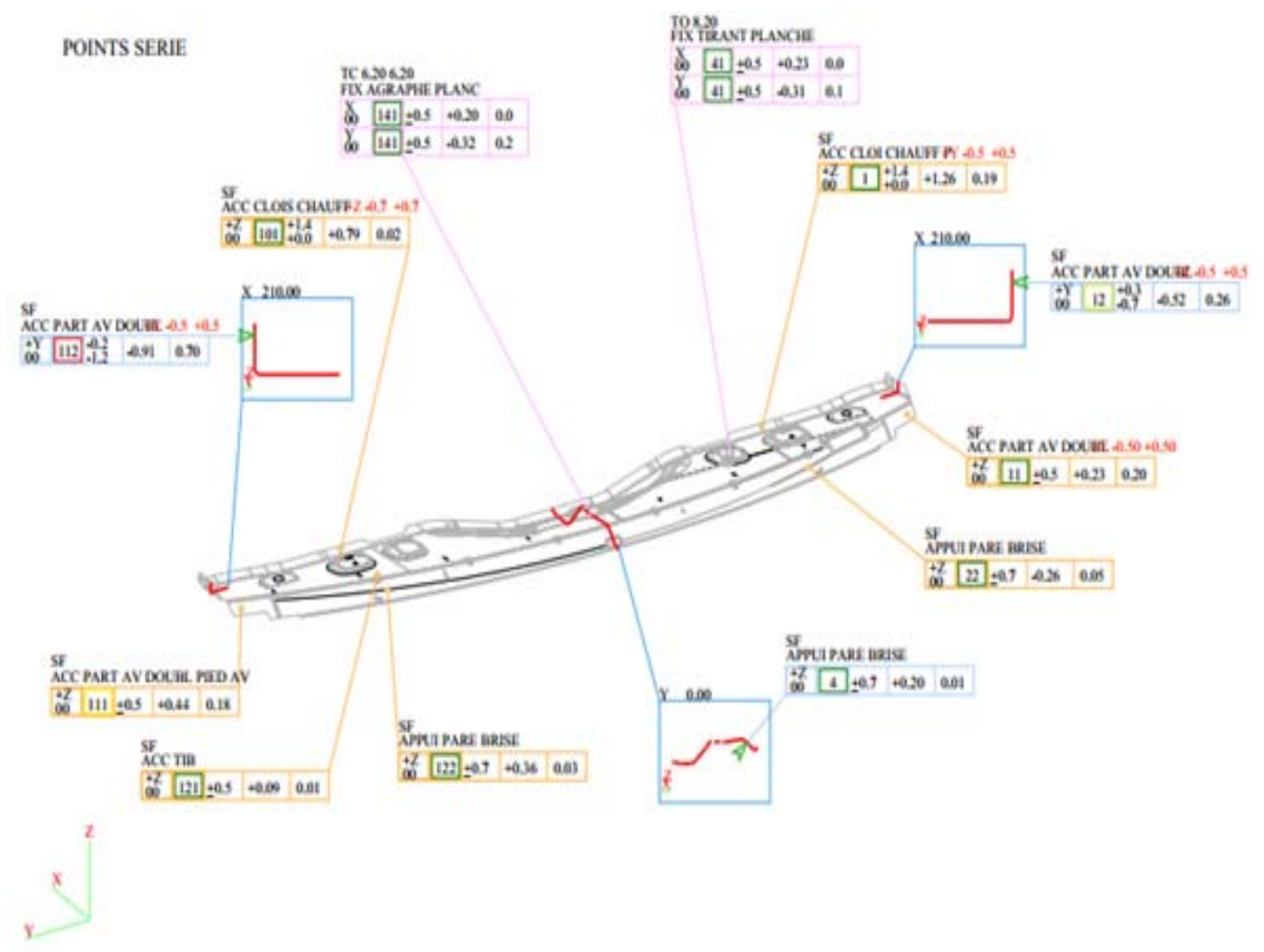

Fig. 8. The mean and extent of control point deviation of the Tibe Closure element (Plate 2/3) 
- Variation of the assembly

In the 3D control room, the control of the assembled box is done for the verification of the conformity of the box. The figure 9 shows an example of a vehicle in the 3D control room. The figure shows the calculated deviation values of the front part of the vehicle chassis with the reference element it is the windshield.

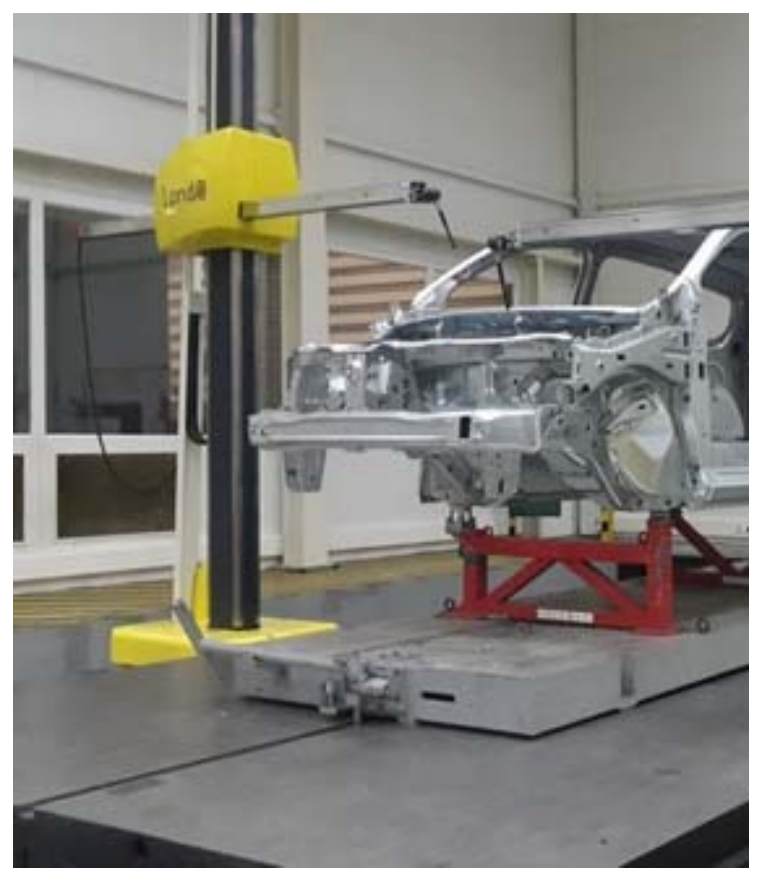

Fig. 9. 3D control room

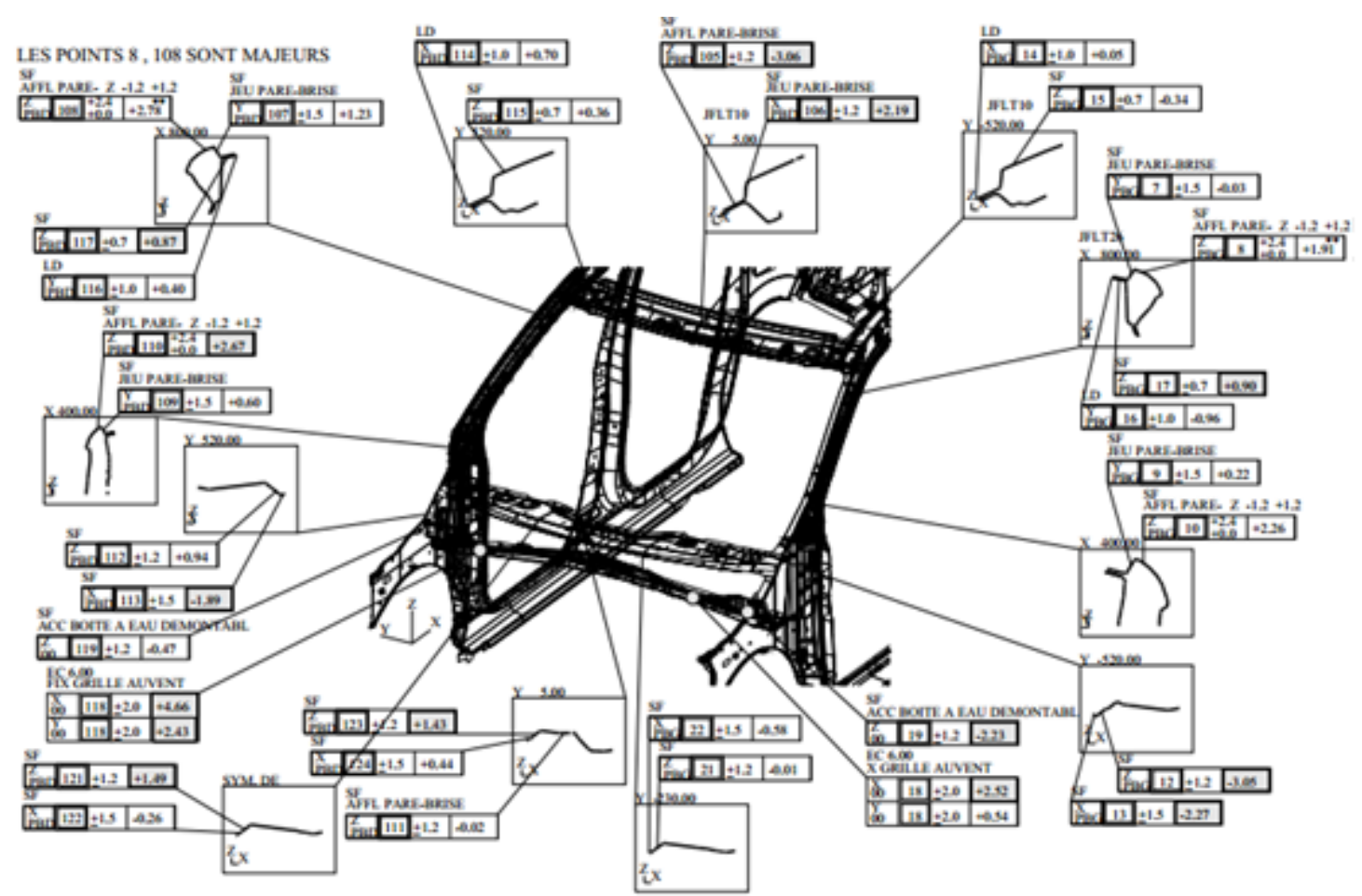

Fig. 10. The standard deviation of the front of the vehicle chassis (Plate 2/2) 


\section{COMPARISON}

The final displacement of all the nodes after the deviation of the springback is recorded for each iteration and for a real case. Two comparisons are made from the result:

$\checkmark$ the simulation with the proposed Method of Influence Coefficients;

$\checkmark$ And a real case in the automotive industry.

Figure 11 shows the results obtained. There is a slight difference between the results which signifies a good precision of the proposed coefficient of influence method for estimating the deformation of flexible assemblies.

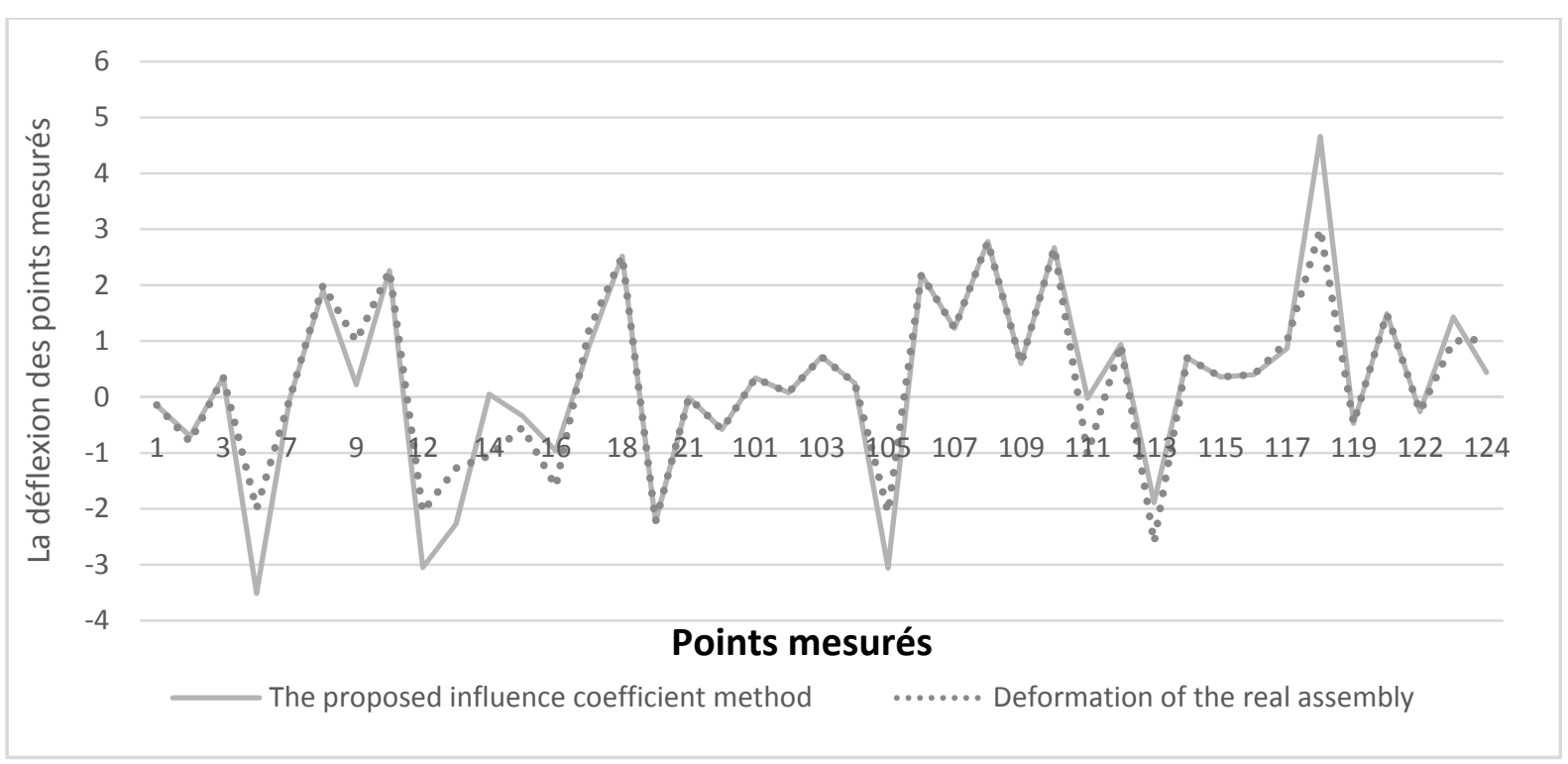

Fig. 11. Comparison between the values of the Method of Influence Coefficients and the actual measurements

\section{EXPLOITATION OF RESULTS}

This process of estimating variations in flexible parts and assemblies can lead to different corrective actions at the design or tolerancing level. The objective remains to obtain a 100\% compliance or assimilability rate for a geometric quality of the parts respecting the process capabilities and a minimum manufacturing cost.

\section{A. Corrective actions on tolerances}

Corrective actions relating to tolerancing will consist in optimizing the tolerance intervals according to the criticality of the defects concerned and the manufacturing costs with respect to the geometric quality required, while respecting the capabilities of the manufacturing processes of these parts. and until an assimilability rate equal to $100 \%$ and a satisfactory manufacturing cost are obtained.

For example, for this case of industrial application, it will be necessary to require an excellent precision on the points of welding and to maximize the functional clearances of these connections

\section{B. Corrective actions on the design}

From a design point of view, the possible corrective actions will be on the Tibe Closure element because of the concentration of defects in this zone and to review the technological choice in order to increase the conformity of the front part of the vehicle.

For the Tibe Closure element Fig. 12 for example, it will be possible to envisage modifying the nature of the connections by defining, for example, oblong holes for the passage of the screws in the cross-shoe links modeled by the connections with the blue color in the figure. In the model, this would result in the suppression of one or more kinematic connection relations linking the degrees of freedom in translation or in rotation, hence the zeroing of a component of the torsors of generalized forces transiting in these bonds, and thus a decrease in the stress of Von Mises in the screws. In reality, this would result in easier bolting of these links and a guarantee of mechanical strength of the screws.

In the original model figure 12, we modified the location of the parts A1 and A2 (figure 13), and fixed on the inside of the boxes of the shock absorbers of the wheels in front of B1 and B2 (figure 14), the final design proposed is presented in the figure 14 . 


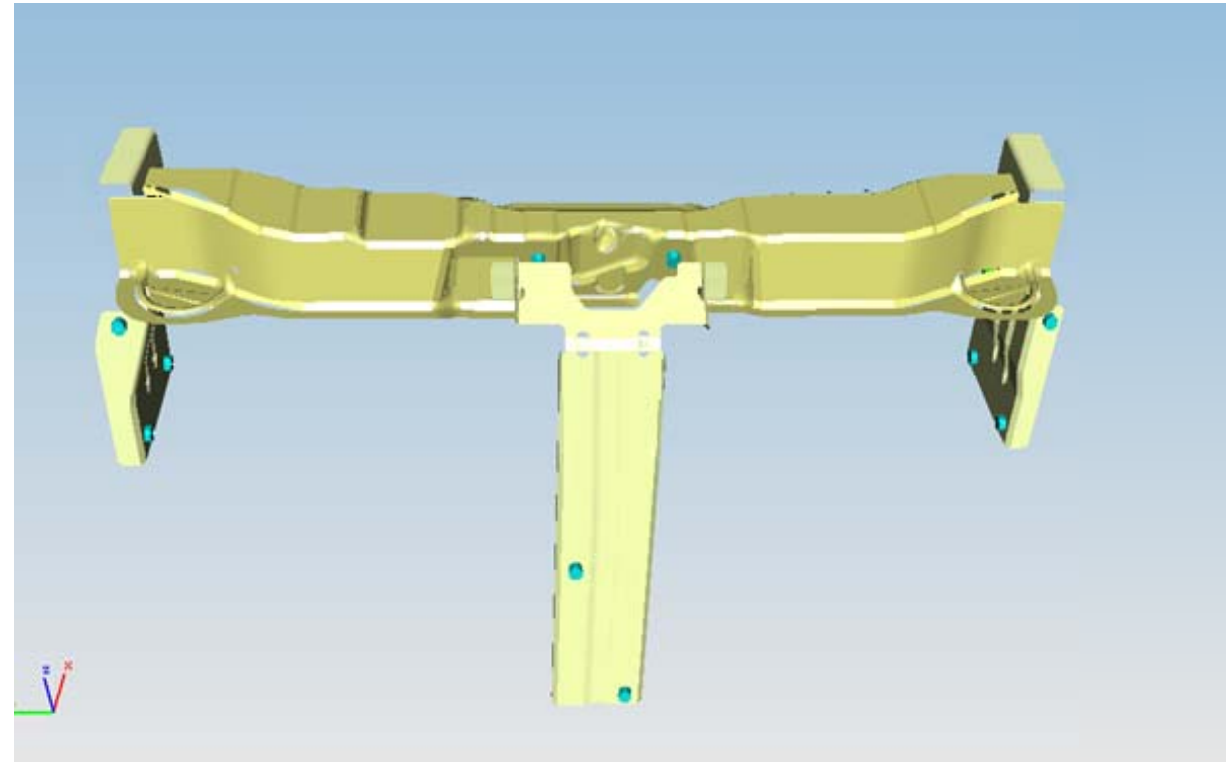

Fig. 12. Geometric model of the original Tibe Closure element

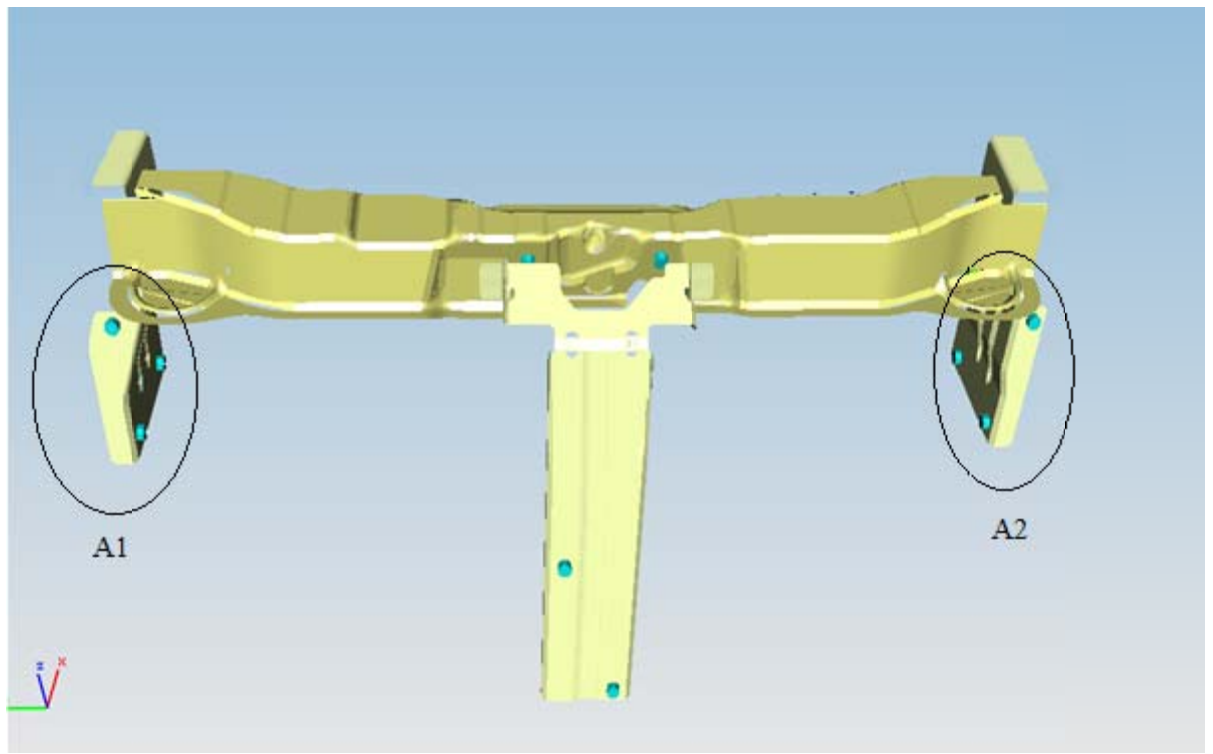

Fig. 13. Geometric model of the element Tibetan Closure original zone A1 and A2

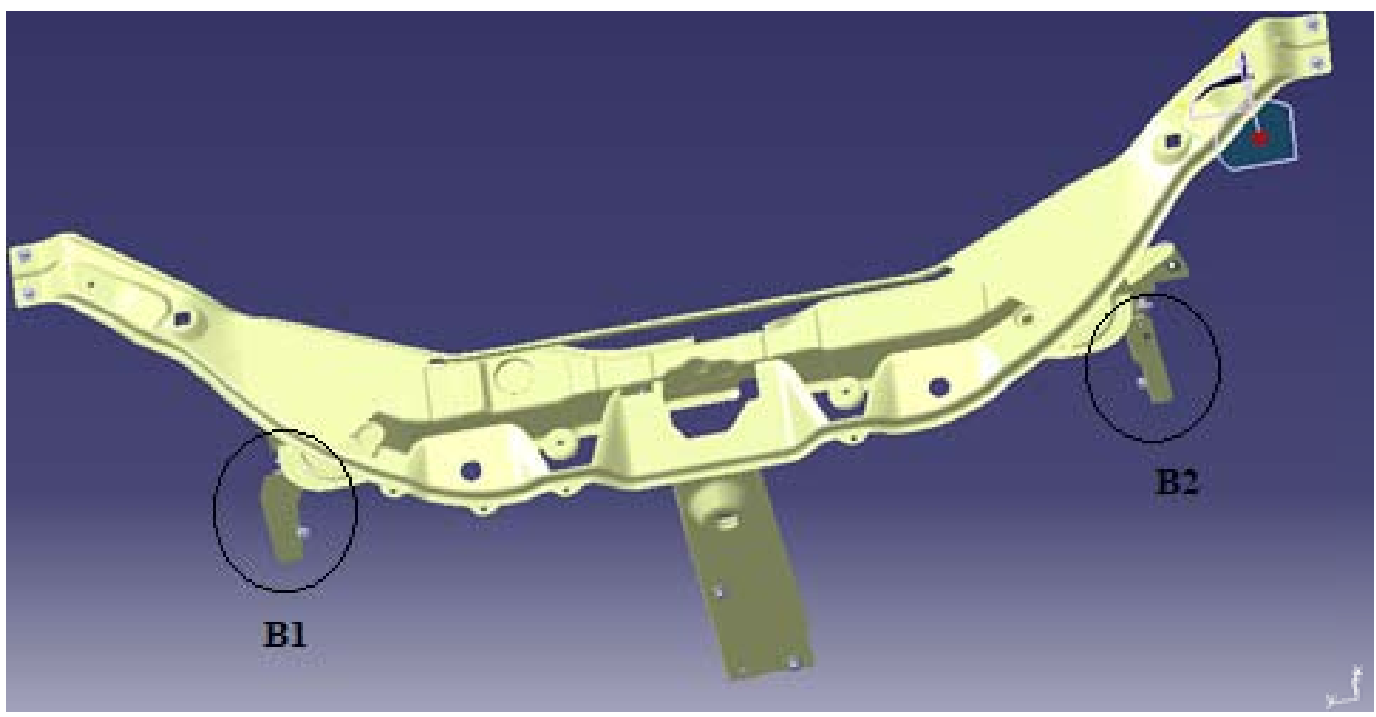

Fig. 14. Geometric Model of CATIA Modified Tube Closure Element 


\section{CONCLUSION}

This example shows the possibility of practicing a tolerance analysis of an assembly of non-rigid parts on automobile assemblies by taking into account the welding effects as well as the shape defects without permission of the penetration between the parts. The minimization of the cost of calculation justifies the use of the method of the coefficients of influence.

\section{REFERENCES}

[1] S. C. Liu et S. J. Hu, «Variation Simulation for Deformable Sheet Metal Assemblies Using Finite Element Methods,» Journal of Manufacturing Science and Engineering, vol. 119, n 13, p. 368, 1 août 1997.

[2] S. Khodaygan, A. Ghasemali et H. Afrasiab, « Statistical Tolerance Analysis of Flexible Assemblies with Contact Effects». No. 201601-1380. SAE Technical Paper, 2016.

[3] S. Dahlström et L. Lindkvist, «Variation Simulation of Sheet Metal Assemblies Using the Method of Influence Coefficients With Contact Modeling,» Journal of Manufacturing Science and Engineering, vol. 129, n 3, p. 615, 1 juin 2007.

[4] M. Royer, « Synthèse des spécifications de fabrication et analyse des tolérances en trois dimensions pour un produit et un process évolutifs au cours de l'industrialisation,» http://www.theses.fr, 962017.

[5] Bihlmaier.B, «Tolerance Analysis of Flexible Assemblies Using Finite Element and Spectral Analysis,». Diss. Brigham Young University. Department of Mechanical Engineering, 1999.

[6] A. Mortensen, "An Integrated Methodology for Statistical Tolerance Analysis of Flexible Assemblies,». Diss. Brigham Young University. Department of Mechanical Engineering, 2002.

[7] A. Sahani, A. Sharma et J. Bajpai, «Tolerance Stack up Analysis of a Mechanical Assembly,» Materials Today: Proceedings, vol. 4, $n^{\circ}$ 12, pp. 1459-1468, 1 janvier 2017.

[8] J. H. Gordis et W. G. Flannelly, «Analysis of stress due to fastener tolerance in assembled components,» AIAA Journal, vol. 32, $\mathrm{n}^{\circ}$ 112 , pp. 2440-2446, 17 décembre 1994.

[9] P. Franciosa, S. Gerbino et S. Patalano, «Simulation of variational compliant assemblies with shape errors based on morphing mesh approach,» The International Journal of Advanced Manufacturing Technology, vol. 53, n 11-4, pp. 47-61, 23 mars 2011.

[10] K. Merkley, «Tolerance Analysis of Compliant Assemblies,» 1998. Diss. Brigham Young University, 1998.

[11] J. Shiu, B. W., Ceglarek, Darek and Shi, «Flexible beam-based modeling of sheet metal assembly for dimensional control,» Transactions of the North American Manufacturing Research Institution of SME, vol. 25 , pp. 49-54,1997.

[12] A. Stricher, «Tolérancement flexible d'assemblages de grandes structures aéronautiques,» École normale supérieure de Cachan - ENS Cachan, 2013.

[13] A. Stricher, L. Champaney, F. Thiebaut, B. Fricero et N. Chevassus, "Tolerance analysis of compliant assemblies using fem simulations and modal description of shape defects. » ASME 2012 11th Biennial Conference on Engineering Systems Design and Analysis. American Society of Mechanical Engineers, 2012.

[14] S. C. Liu et S. J. Hu, «Variation Simulation for Deformable Sheet Metal Assemblies Using Finite Element Methods,» Journal of Manufacturing Science and Engineering, vol. 119, n 13, p. 368, 1 août 1997.

[15] K. Wärmefjord, R. Söderberg et L. Lindkvist, «Simulation of Variation in Assembly Forces Due to Variation in Spot Weld Position,» pp. 473-482, 2013.

[16] A. Hashemian, \& B. M. Imani. « An improved sensitivity-free probability analysis in variation assessment of sheet metal assemblies, ». Journal of Engineering Design, vol 25(10-12), pp 346-366, 2014.

[17] A. Hashemian., \& B. Moetakef Imani, Nonlinear variation analysis of compliant sheet metal assemblies including effect of surface continuity in components. In Applied Mechanics and Materials Vol. 532, pp. 503-509. Trans Tech Publications, 2014.

[18] M. Zhang, «Discrete shape modeling for geometrical product specification: contributions and applications to skin model simulation, » École normale supérieure de Cachan - ENS Cachan, 2011

[19] A. hafsa, C. mouhssine, A. driss, B. said, «Tolerance analysis of springback of compliant assemblies by contact modeling and welding distortion, ». International Journal of Engineering \& Technology Vol 7, No 1, 2018.

[20] A. hafsa, C. mouhssine, A. driss, B. said, «Optimization tolerancing of surface in flexible parts and assembly: Influence Coefficient Method with shape defects, ». International Journal of Engineering \& Technology. Vol 7, No 1, 2018.

[21] H. Atik, M. Chahbouni, S. Boutahari, D. Amegouz « The state of art and a comparative study of the deformable mechanisms in the domain of tolerance, » International Journal of Advanced Information Science and Technology (IJAIST), vol.5 pp. 12-19, 2016.

\section{AUTHOR PROFILE}

Hafsa Atik PhD student in Mechanics Engineering from The University sidimohamed ben abdelah, of Department of Mechanical and Production Engineering and Industrial Maintenance at the School of Technology, fez,Atik received her Master degree in Mechanics Engineering from The University sidimohamed ben abdelah, fez, in 2014. Her areas of research include Tolerancing, tolerance analysis, and optimization of tolerances in rigid and flexible mechanism.

Mouhssine Chahbouni received his $\mathrm{PhD}$ degree in Mechanics Engineering from The University sidimohamed ben abdelah, fez, in 2016. Dr. Chahbouni received his Engineering Degree in Industrial Engineering from National School of Applied Sciences of Fez (ENSA - Fez),Maroc, in. Currently, Dr. Chahbouni is a Research professor working as Professor of mechanic of Department of Mechanical and Production Engineering and Industrial Maintenance at the School of Technology, fez. His areas of research include Tolerancing, tolerance analysis, and optimization of tolerances in rigid and flexible mechanisms.

Driss Amegouz received his PhD degree in Mechanics Engineering from The University sidi mohamed ben abdelah, fez, in 2002. Dr. Amegouz received his Diploma Engineer in Production System from National School of Engineers of Metz, France, in. Currently, Dr. Amegouz is a Research professor (Grade PES) in the Department of Department of Mechanical and Production Engineering and Industrial Maintenance at the School of Technology, fez. His areas of research include Tolerancing, tolerance analysis, and optimization of tolerances in rigid and flexible mechanisms. 
Said Boutahari received his PhD degree in Mechanics Engineering from The University sidi mohamed ben abdelah, fez, in 2007. Dr. Boutahari received his Diploma Engineer from the National School of Mineral Industry (ENIM), Morocco, in. Currently, Dr. Boutahari is a Research professor (Grade qualified teacher) in the Department of Department of Mechanical and Production Engineering and Industrial Maintenance at the School of Technology, fez. His areas of research include Tolerancing, tolerance analysis, and optimization of tolerances in rigid and flexible mechanisms. 